\title{
PENERAPAN RESOURCE LEVELING DENGAN METODE ALGORITMA GENETIKA PADA PROYEK KONSTRUKSI DI JAKARTA
}

\author{
Hendy ${ }^{1}$, Henny Wiyanto \\ ${ }^{1}$ Program Studi Sarjana Teknik Sipil, Universitas Tarumanagara, Jl. Letjen S. Parman No.1 Jakarta \\ Email: h_mudyono@yahoo.com \\ ${ }^{2}$ Program Studi Sarjana Teknik Sipil, Universitas Tarumanagara, Jl. Letjen S. Parman No.1 Jakarta \\ Email:hennyw@ft.untar.ac.id
}

\begin{abstract}
ABSTRAK
Tenaga kerja merupakan salah satu sumber daya yang berpengaruh terhadap penyelesaian proyek konstruksi. Pada fase konstruksi sering kali muncul masalah yang berkaitan dengan pengaturan tenaga kerja. Fluktuasi kebutuhan tenaga kerja yang tajam menyebabkan kebutuhan puncak tenaga kerja harian menjadi tinggi. Untuk itu diperlukan suatu cara untuk mengatasi fluktuasi yang tajam tersebut yaitu dengan perataan tenaga kerja. Perataan tenaga kerja menggunakan metode algoritma genetika dengan bantuan program Evolver. Hasil penelitian pada proyek X menunjukkan bahwa perataan tenaga kerja pada tenaga kerja (tukang batu, tukang kayu, dan tukang besi) berpengaruh terhadap kebutuhan puncak tenaga kerja harian. Terjadi penurunan kebutuhan puncak tenaga kerja tukang besi dari 77 orang menjadi 70 orang. Efisiensi yang terjadi adalah 9,1\%. Dapat disimpulkan bahwa perataan tenaga kerja yang dilakukan pada penelitian ini dapat mengurangi kebutuhan puncak tenaga kerja.
\end{abstract}

Kata kunci: fluktuasi, perataan tenaga kerja, proyek konstruksi, algoritma genetika

\section{PENDAHULUAN}

\section{Latar Belakang}

Pembangunan infrastruktur di Indonesia sangatlah pesat di segala bidang. Oleh karenanya, sejalan dengan perkembangan ini, diperlukan pengawasan dalam perencanaan dan pelaksanaan pembangunan proyek konstruksi agar dapat mencapai tujuan dan harapan yang diinginkan.

Karakteristik volume pekerjaan yang tersedia pada proyek konstruksi yang bersifat tidak stabil menyebabkan berfluktuasinya kebutuhan terhadap tenaga kerja. Selain itu, pada penjadwalan banyak terjadi overlap antara aktivitas satu dengan aktivitas lainnya, sehingga menyebabkan kebutuhan puncak tenaga kerja harian menjadi tinggi.

Pemerataan sumber daya manusia (resource leveling) merupakan salah satu usaha yang dilakukan untuk menghindari fluktuasi yang tajam tersebut. Tujuan dilakukannya pemerataan adalah untuk meperoleh pemanfaatan yang optimal dari sumber daya manusia dan untuk menghindari saat dimana kebutuhan tenaga menjadi sangat tinggi atau sangat rendah (Raja and Kumanan, 2007).

\section{Maksud dan tujuan}

Maksud dari penelitian ini adalah menghitung jumlah perbedaan tenaga kerja sebelum dan sesudah dilakukan resource leveling dengan metode Algoritma Genetika. Sedangkan tujuan dari penelitian ini adalah mengetahui banyak perbedaan tenaga kerja sebelum dan sedudah dilakukan resource leveling dengan metode Algoritma Genetika.

\section{Ruang lingkup}

Ruang lingkup dari penelitian ini adalah perataan tenaga kerja yang dilakukan dengan metode Algoritma Genetika. Data yang dikumpulkan adalah data penjadwalan proyek yang dapat menunjukkan informasi jenis kegiatan, durasi kegiatan, dan keterkaitan aktivitas beserta keterangan kebutuhan tenaga kerja per hari untuk setiap kegiatan. 


\section{Batasan masalah}

Batasan masalah pada penelitian ini adalah waktu mulai daan selesai pengerjaan proyek yang digunakan dalam penelitian ini adalah tetap dan tidak dapat diperpanjang. Durasi setiap kegiatan didalam proyek adalah tetap. Produktivitas pekerja setiap kegiatan dianggap sama.

\section{DASAR TEORI}

\section{Perataan sumber daya (resource leveling)}

Sering terjadi pada saat tertentu proyek terlalu banyak menyedot sumber daya (tenaga kerja) dan pada saat yang lain terlalu sedikit membutuhkan sumber daya sehingga pemakaian sumber daya ini tidak merata. Untuk itu harus dilakukan perataan agar tidak ada sumber daya yang dibiarkan (terutama tenaga kerja) setelah pada saat tertentu diperlukan.

Soeharto (2001) menyatakan, naik turunnya pekerjaan baik yang disebabkan oleh ada atau tidaknya kontrak atau usaha yang ditangani, maupun oleh sifat kegiatan proyek sendiri yang bersifat dinamis, mengakibatkan jumlah keperluan tenaga kerja yang berubah-ubah selama siklus proyek, baik kuantitas maupun kualitasnya. Untuk menjaga efisiensi, maka jumlah tenaga kerja harus disesuaikan dengan perubahan tersebut. Caranya adalah dengan sistem multiguna (multicraft), yaitu seorang tenaga kerja dilatih dan ditingkatkan kemampuan agar dapat menangani berbagai macam pekerjaan. Cara lain adalah dengan meratakan pemakaian tenaga kerja (resource leveling), tujuannya adalah untuk mencegah terjadinya gejolak naik-turun (fluktuasi) yang tajam.

Fluktuasi kebutuhan sumber daya yang berlebihan menyebabkan berbagai masalah, misalnya pengadaan dan pemulangan pekerja secara tidak beraturan, penurunan efisiensi kerja di lapangan, dan penurunan semangat kerja. Keadaan ideal tercapai apabila bentuk histogram pembebanan sumber daya adalah rata. Keadaan optimum perlu dicari dengan pengaturan jadwal kerja agar kebutuhan sumber daya mempunyai fluktuasi yang sama. Hal ini dilakukan dengan menggeser jadwal pekerjaan yang memiliki float, sehingga tidak mengganggu penyelesaian proyek secara keseluruhan.

\section{Resource leveling metrics}

Metrik perataan sumber daya telah dikembangkan untuk dapat menghitung secara langsung dampak yang dihasilkan dari fluktuasi sumber daya pada suatu proyek dari segi produktivitas dan biaya (El-Rayes and Jun, 2009). Fluktuasi ini dapat dibedakan menjadi 2 berdasarkan dampak yang dihasilkan terhadap efisiensi penggunaan tenaga kerja yaitu : (1) Fluktuasi yang dapat diterima / acceptable fluctiation dan (2) fluktuasi yang tidak diinginkan / undesirable fluctuation.

Fluktuasi yang dapat diterima adalah fluktuasi yang membentuk grafik naik dan kemudian turun yang memiliki puncak di bagian atas grafik seperti bentuk gunung pada histrogram pekerja, Histrogram yang membentuk grafik naik diawal dan kemudian turun diakhir akan meminimalisasi tugas kontraktor untuk memanggil, mengistirahatkan, dan kemudian memanggil kembali pekerja (Matilla dan Abraham, 1998).

Fluktuasi yang tidak diinginkan membentuk grafik turun yang bersifat sementara pada histrogram pekerja. Jenis fluktuasi ini dapat digambarkan seperti lembah pada histrogram kebutuhan pekerja. Pada jenis fluktuasi ini, kontraktor dipaksa untuk : (1) memulangkan pekerja dan kemudian memanggilnya kembali disaat dibutuhkan, atau (2) menahan pekerja yang menganggur di proyek sampai ia dibutuhkan kembali di hari selanjutnya. Maka, untuk meningkatkan produktivitas pekerja dan mengurangi biaya, jenis fluktuasi ini harus dihitung dan diminimalisasi dengan cara menghitung: (1) Release and Re-Hire (RRH) dan (2) Resources Idle Days (RID).

Release and Re-Hire Metric: RRH, adalah metrik yang digunakan untuk menghitung jumlah sumber daya yang perlu dipulangkan sementara saat kebutuhan pekerja menurun dan kemudian memanggilnya kembali saat kebutuhan tenaga kerja meningkatkan kembali. RRH dapat dihitung dengan persamaan:

$$
\begin{gathered}
\mathrm{RRH}=H-\mathrm{MRD}=\frac{1}{2} \times H R-\mathrm{MRD} \\
H R=\left[r_{1}+\sum_{t=1}^{T-1}\left|r_{t}-r_{t+1}\right|+r_{T}\right]
\end{gathered}
$$

dengan $\mathrm{H}=$ total kenaikan permintaan sumber daya harian, $\mathrm{HR}=$ total fluktuasi sumber daya harian, $\mathrm{T}=$ total durasi proyek, $\mathrm{r}_{\mathrm{t}}=$ jumlah sumber daya pada hari ke- $t, \mathrm{r}_{\mathrm{t}+1}=$ permintaan sumber daya pada hari ke- $(t+1)$, $\mathrm{r}_{\mathrm{T}}=$ permintaan sumber daya pada hari akhir proyek $(\mathrm{T})$. 
Resource Idle Days Metric: RID, adalah metrik yang digunakan untuk menghitung jumlah sumber daya yang menganggur (tidak produktif) selama proyek berlangsung. Metrik RID dapat dihitung dengan persamaan:

$$
\mathrm{RID}=\sum_{i=1}^{T}\left[\operatorname{Min}\left\{\operatorname{Max}\left(r_{1}, r_{2}, \ldots, r_{t}\right), \operatorname{Max}\left(r_{t}, r_{t+1}, \ldots, r_{T}\right)\right\}-r_{t}\right]
$$

dengan $\mathrm{T}=$ total durasi proyek, dan $\mathrm{r}_{t}=$ jumlah kebutuhan sumber daya pada hari ke- $t$.

\section{Model optimasi}

Metrik pemerataan sumber daya yang dikembangkan oleh El-Rayes dan Jun ini memiliki tujuan untuk meningkatkan efisiensi penggunaan sumber daya (memaksimalkan penggunaan sumber daya) dengan cara menurunkan angka RRH atau RID. Tujuan selanjutnya adalah menurunkan angkahkebutuhan maksimun / kebutuhan puncak tenaga kerja (MRD). Oleh karenanya, sebuah fungsi optimasi telah dirancang untuk menggabungkan bobot perencanaan $\left(W_{l}\right)$ dan $\left(W_{2}\right)$ untuk menurunkan angka RRH atau RID yang sekaligus meminalisasi angka kebutuhan puncak tenaga kerja (MRD) dengan persamaan sebagai berikut:

$$
\operatorname{Min}\left(W_{l} \mathrm{RRH}+W_{2} \mathrm{MRD}\right) \text { atau } \operatorname{Min}\left(W_{l} \mathrm{RID}+W_{2} \mathrm{MRD}\right)
$$

dengan $\mathrm{W}_{1}$ adalah bobot atau kepentingan relatif untuk RRH atau RID sedangkan $\mathrm{W}_{2}$ adalah bobot atau kepentingan relatif untuk MRD.

\section{Algoritma genetika}

Algoritma genetika adalah simulasi dari proses evolusi Darwin dan operasi genetika atas kromosom (Kusumadewi, 2003). Algoritma genetika mengikuti prosedur atau tahap-tahap yang menyerupai proses evolusi, yaitu adanya proses seleksi, crossover dan mutasi. Pada setiap generasi, himpunan baru dari deretan individu dibuat berdasarkan kecocokan pada generasi sebelumnya (Goldberg, 1989). Istilah-istilah penting yang perlu diketahui dalam melakukan penyelesaian masalah menggunakan algoritma genetika yaitu:

a. Genotype (Gen) adalah sebuah nilai yang menyatakan satuan dasar yang membentuk suatu arti tertentu dalam satu kesatuan gen yang dinamakan kromosom. Dalam algoritma genetika, gen ini dapat berupa biner, integer, karakter ataupun kombinatorial.

b. Kromosom adalah gabungan gen-gen yang membentuk nilai tertentu

c. Alelle merupakan nilai dari gen

d. Individu menyatakan suatu nilai atau keadaan yang menyatakan salah satu solusi yang mungkin dari permasalahan yang diangkat.

e. Populasi merupakan sekumpulan individu yang akan diproses berdama dalam satu siklus proses evolusi.

f. Generasi menyatakan satu siklus proses evolusi atau satu interasi didalam algoritma genetik.

Algoritma genetika sangat tepat digunakan untuk menyelesaikan permasalahan optimasi yang kompleks. Didalam algoritma genetika, solusi permasalahan direpresentasikan ke dalam bentuk kromosom. Tiga aspek yang penting untuk penggunaan algoritma genetika yaitu :

1. Fungsi fitness.

2. Implementasi representasi genetik berupa kromosom.

3. Implementasi operasi genetik berupa operator crossover dan mutasi

Algoritma genetika membutuhkan beberapa parameter yang merupakan parameter kontrol genetik algoritma yang terdiri dari ukuran populasi (popsize), peluang crossover $\left(\mathrm{P}_{\mathrm{c}}\right)$, dan peluang mutasi $\left(\mathrm{P}_{\mathrm{m}}\right)$. Ukuran populasi (popsize) menunjukkan jumlah kromosom yang terdapat didalam populasi. Peluang crossover $\left(\mathrm{P}_{\mathrm{c}}\right)$ menunjukkan kemungkinan crossover yang terjadi antara dua kromosom. Peluang mutasi $\left(\mathrm{P}_{\mathrm{m}}\right)$ menunjukkan kemungkinan mutasi yang terjadi antara pada gen-gen yang menyusun sebuah kromosom. Nilai parameter ini ditentukan juga berdasarkan permasalahan yang akan dipecahkan (Kusumadewi, 2005). 
Ada beberapa rekomendasi yang bisa digunakan antara lain:

1. Untuk permasalahan yang memiliki kawasan solusi cukup besar, De Jong merekomendasikan untuk nilai parameter kontrol:

(popsize; $\left.\mathrm{P}_{\mathrm{c}} ; \mathrm{P}_{\mathrm{m}}\right)=(50 ; 0,6 ; 0,001)$

2. Bila rata-rata fitness setiap generasi digunakan sebagai indikator, maka Grefenstette merekomendasikan: (popsize $\left.; \mathrm{P}_{\mathrm{c}} ; \mathrm{P}_{\mathrm{m}}\right)=(30 ; 0,95 ; 0,01)$

3. Bila fitness dari individu terbaik dipantau pada setiap generasi, maka usulannya adalah: (popsize; $\left.\mathrm{P}_{\mathrm{c}} ; \mathrm{P}_{\mathrm{m}}\right)=(80 ; 0,45 ; 0,01)$

4. Ukuran populasi sebaiknya tidak lebih kecil dari 30, untuk sembarang jenis permasalahan.

\section{METODOLOGI PENELITIAN}

\section{Metode pengumpulan data}

Data yang digunakan berupa data master schedule proyek yang memberikan informasi jenis kegiatan, durasi kegiatan, dan keterkaitan kegiatan serta keterangan jumlah kebutuhan tenaga kerja yang dibutuhkan setiap harinya untuk tiap jenis kegiatan. Data yang ada kemudian dibuatlah barchart untuk menngetahui alokasi sumber daya disetiap pekerjaan dan dibentuk histogram tenaga kerja.

Tabel 1. Data Penjadwalan Lantai B5-GF

\begin{tabular}{|c|c|c|c|c|}
\hline ID & Kegiatan & Durasi (Hari) & Predecessors & Pekerja (Orang) \\
\hline 2370 & ZONA 1 & 14 & & \\
\hline 2371 & KOLOM & 5 & & \\
\hline 2372 & Pembesian & 3 & & 26 \\
\hline 2373 & Bekisting & 3 & $2372 \mathrm{FS}-2 \mathrm{~d}$ & 16 \\
\hline 2374 & Pengecoran & 1 & 2373 & 5 \\
\hline 2375 & SHEARWALL & 8 & & \\
\hline 2376 & Pembesian & 4 & $2372 S S+1 d$ & 21 \\
\hline 2377 & Bekisting & 4 & $2376 \mathrm{FS}-1 \mathrm{~d}$ & 11 \\
\hline 2378 & Pengecoran & 1 & 2364FF, 2377 & 5 \\
\hline 2379 & BALOK DAN PELAT & 7 & & \\
\hline 2380 & Bekisting & 4 & $2378 \mathrm{FS}-2 \mathrm{~d}$ & 50 \\
\hline 2381 & Pembesian & 4 & $2380 \mathrm{FS}-2 \mathrm{~d}$ & 30 \\
\hline 2382 & Pengecoran & 1 & 2381 & 15 \\
\hline 2383 & ZONA 2 & 14 & & \\
\hline 2384 & KOLOM & 5 & & \\
\hline 2385 & Pembesian & 3 & $2376 S S+1 d$ & 23 \\
\hline 2386 & Bekisting & 3 & $2385 \mathrm{FS}-2 \mathrm{~d}$ & 14 \\
\hline 2387 & Pengecoran & 1 & 2386 & 5 \\
\hline 2388 & SHEARWALL & 8 & & \\
\hline 2389 & Pembesian & 4 & $2385 S S+1 d$ & 7 \\
\hline 2390 & Bekisting & 4 & $2389 \mathrm{FS}-1 \mathrm{~d}$ & 11 \\
\hline 2391 & Pengecoran & 1 & $2387 \mathrm{FF}, 2390$ & 5 \\
\hline 2392 & BALOK DAN PELAT & 7 & & \\
\hline 2393 & Bekisting & 4 & $2391 \mathrm{FS}-2 \mathrm{~d}$ & 28 \\
\hline 2394 & Pembesian & 4 & $2393 \mathrm{FS}-2 \mathrm{~d}$ & 17 \\
\hline 2395 & Pengecoran & 1 & 2394 & 10 \\
\hline 2396 & ZONA 3 & 14 & & \\
\hline 2397 & KOLOM & 5 & & \\
\hline 2398 & Pembesian & 3 & $2389 \mathrm{SS}+1 \mathrm{~d}$ & 26 \\
\hline 2399 & Bekisting & 3 & $2398 \mathrm{FS}-2 \mathrm{~d}$ & 16 \\
\hline 2400 & Pengecoran & 1 & 2399 & 5 \\
\hline 2401 & SHEARWALL & 8 & & \\
\hline 2402 & Pembesian & 4 & $2398 \mathrm{SS}+1 \mathrm{~d}$ & 21 \\
\hline 2403 & Bekisting & 4 & $2402 \mathrm{FS}-1 \mathrm{~d}$ & 11 \\
\hline 2404 & Pengecoran & 1 & $2400 \mathrm{FF}, 2403$ & 5 \\
\hline 2405 & BALOK DAN PELAT & 7 & & \\
\hline 2406 & Bekisting & 4 & $2404 \mathrm{FS}-2 \mathrm{~d}$ & 50 \\
\hline 2407 & Pembesian & 4 & $2406 \mathrm{FS}-2 \mathrm{~d}$ & 30 \\
\hline 2408 & Pengecoran & 1 & 2407 & 15 \\
\hline
\end{tabular}

Tabel 2. Data Penjadwalan Lantai 2 - top roof

\begin{tabular}{|c|c|c|c|c|}
\hline ID & Kegiatan & $\begin{array}{c}\text { Durasi } \\
\text { (Hari) }\end{array}$ & Predecessors & $\begin{array}{l}\text { Pekerja } \\
\text { (Orang) }\end{array}$ \\
\hline 2610 & ZONA 1 & 99 & & \\
\hline 2611 & KOLOM & 4 & & \\
\hline 2612 & Pembesian & 2 & $2582 \mathrm{FS}+2 \mathrm{~d}$ & 28 \\
\hline 2613 & Bekisting & 2 & 2612FS - 1d & 32 \\
\hline 2614 & Pengecoran & 1 & 2613 & 5 \\
\hline 2615 & SHEARWALL & 6 & & \\
\hline 2616 & Pembesian & 3 & $2612 S S+1 d$ & 20 \\
\hline 2617 & Bekisting & 3 & $2616 \mathrm{FS}-1 \mathrm{~d}$ & 16 \\
\hline 2618 & Pengecoran & 1 & 2614FF, 2617 & 5 \\
\hline 2619 & BALOK DAN PELAT & 6 & & \\
\hline 2620 & Bekisting & 4 & $2618 \mathrm{FS}-4 \mathrm{~d}$ & 57 \\
\hline 2621 & Pembesian & 3 & $2620 \mathrm{FS}-2 \mathrm{~d}$ & 37 \\
\hline 2622 & Pengecoran & 1 & 2621 & 15 \\
\hline 2623 & ZONA 2 & 9 & & \\
\hline 2624 & KOLOM & 4 & & \\
\hline 2625 & Pembesian & 2 & $2595 \mathrm{FS}+2 \mathrm{~d}, 2616 \mathrm{SS}+1 \mathrm{~d}$ & 24 \\
\hline 2626 & Bekisting & 2 & $2625 \mathrm{FS}-1 \mathrm{~d}$ & 27 \\
\hline 2627 & Pengecoran & 1 & 2626 & 5 \\
\hline 2628 & SHEARWALL & 6 & & \\
\hline 2629 & Pembesian & 3 & $2625 S S+1 d$ & 6 \\
\hline 2630 & Bekisting & 3 & $2629 \mathrm{FS}-1 \mathrm{~d}$ & 5 \\
\hline 2631 & Pengecoran & 1 & $2627 \mathrm{FF}, 2630$ & 5 \\
\hline 2632 & BALOK DAN PELAT & 6 & & \\
\hline 2633 & Bekisting & 4 & $2631 \mathrm{FS}-4 \mathrm{~d}$ & 32 \\
\hline 2634 & Pembesian & 3 & $2633 \mathrm{FS}-2 \mathrm{~d}$ & 21 \\
\hline 2635 & Pengecoran & 1 & 2634 & 10 \\
\hline 2636 & ZONA 3 & 9 & & \\
\hline 2637 & KOLOM & 4 & & \\
\hline 2638 & Pembesian & 2 & $2608 \mathrm{FS}+2 \mathrm{~d}, 2696 \mathrm{SS}+1 \mathrm{~d}$ & 28 \\
\hline 2639 & Bekisting & 2 & $2638 \mathrm{FS}-1 \mathrm{~d}$ & 32 \\
\hline 2640 & Pengecoran & 1 & 2639 & 5 \\
\hline 2641 & SHEARWALL & 6 & & \\
\hline 2642 & Pembesian & 3 & $2638 \mathrm{SS}+1 \mathrm{~d}$ & 20 \\
\hline 2643 & Bekisting & 3 & $2642 \mathrm{FS}-1 \mathrm{~d}$ & 16 \\
\hline 2644 & Pengecoran & 1 & $2640 \mathrm{FF}, 2643$ & 5 \\
\hline 2645 & BALOK DAN PELAT & 6 & & \\
\hline 2646 & Bekisting & 4 & $2644 \mathrm{FS}-4 \mathrm{~d}$ & 57 \\
\hline 2647 & Pembesian & 3 & $2646 \mathrm{FS}-2 \mathrm{~d}$ & 37 \\
\hline 2648 & Pengecoran & 1 & 2647 & 15 \\
\hline
\end{tabular}

Proyek yang ditinjau untuk penelitian ini adalah proyek high rise building yang terletak di daerah Jakarta Selatan yang dilaksanakan oleh kontraktor X. Penelitian difokuskan pada tower 3 yang digunakan sebagai apartemen. Dalam penjadwalan proyek X ini, penjadwalan lantai B5 tipikal hingga GF dan penjadwalan lantai 2 tipikal hingga top roof. Pekerjaan struktur atas pada proyek X tower 3, dibagi menjadi 3 zona. Setiap zona memiliki jadwal yang sama yang terdiri dari pekerjaan struktur kolom, pekerjaan struktur shearwall, dan pekerjaan struktur dan pelat. Masing-masing pekerjaan struktur terdiri dari kegiatan pembesian yang dilakukan oleh tukang besi, kegiatan bekisting dilakukan oleh tukang kayu, dan kegiatan pengecoran dilakukan oleh tukang batu. 


\section{Metode analisis data}

Data barchart yang telah dibentuk kemudian dilakukan perataan tenaga kerja dengan menggunakan metode algoritma genetika. Proses perataan dibantu program Evolver 7.5.

\section{HASIL DAN PEMBAHASAN}

Perataan tenaga kerja hanya dilakukan pada kegiatan-kegiatan yang tidak kritis dengan mengituki aturan tie-breaking (El-Rayes dan Jun, 2009) yaitu sebagai berikut :

1. Pilih aktivitas tidak kritis terakhir $\left(n^{*}\right)$ dengan waktu LF terakhir yang belum bergeser dalam siklus pergeseran sebelumnya.

2. Jika aturan i) menghasilkan nilai yang sama (tie), maka pilih aktivitas tidak kritis $\left(n^{*}\right)$ dengan float terkecil.

3. Jika aturan ii) juga menghasilkan nilai yang sama (tie), pilih aktivitas tidak kritis terbaru $\left(n^{*}\right)$ yang memiliki urutan terakhir $(n)$

Berdasarkan penjadwalan dengan metode PDM, diketahui bahwa kegiatan kritis untuk zona 1, 2, dan 3 pada lantai B5 hingga lantai GF terjadi pada semua kegiatan shearwall dan semua kegiatan balok dan pelat. Kegiatan tidak kritis terjadi pada kegiatan pembesian, bekisting, dan pengecoran kolom. Hal ini sama terjadi pada penjadwalan lantai 2 hingga lantai top roof.

\section{Hasil resource leveling lantai B5 - GF}

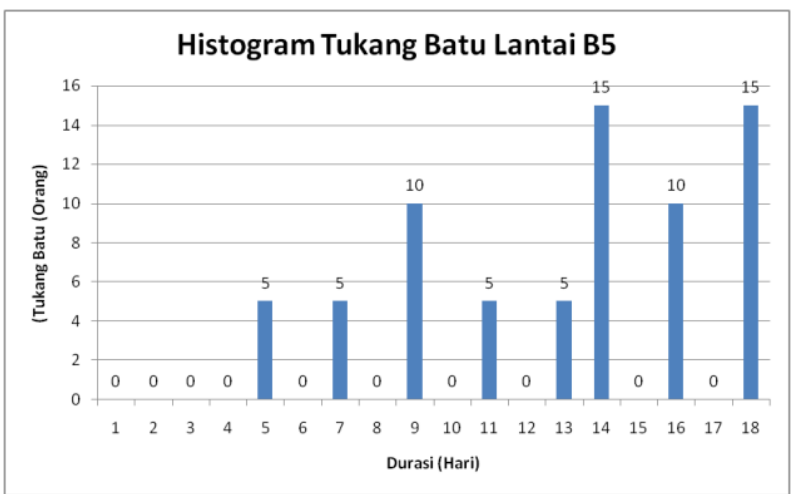

Gambar 1. Histogram tenaga kerja tukang batu lantai B5 sebelum Resource Leveling

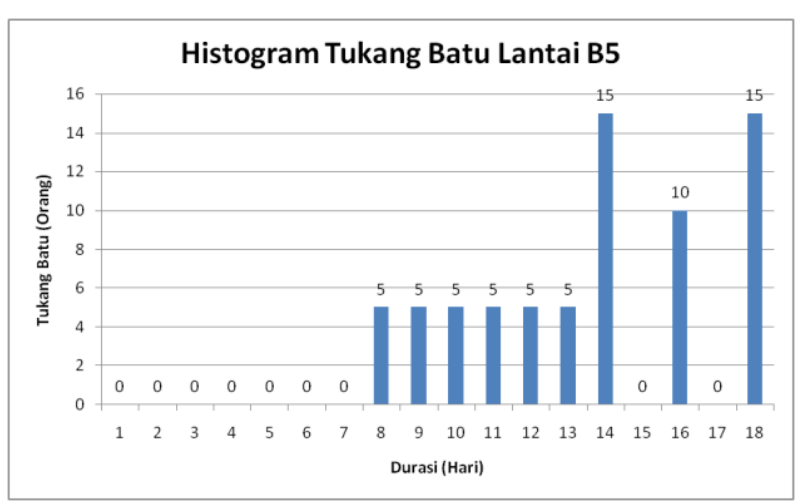

Gambar 2. Histogram tenaga kerja tukang batu lantai B5 setelah Resource Leveling

Pada penjadwalan awal pekerjaan pengecoran lantai B5 yang dilakukan oleh tukang batu, jumlah maksimum permintaan tenaga kerja tukang batu per hari selama proyek berlangsung (MRD) untuk lantai B5 adalah 15 orang dan total jumlah tenaga kerja per hari yang tidak produktif (RID) untuk lantai B5 adalah 75 orang, seperti terlihat pada histogram gambar 1 . Setelah dilakukan perataan tenaga kerja, nilai RID tukang batu menurun menjadi 35 orang dengan nilai MRD tetap.

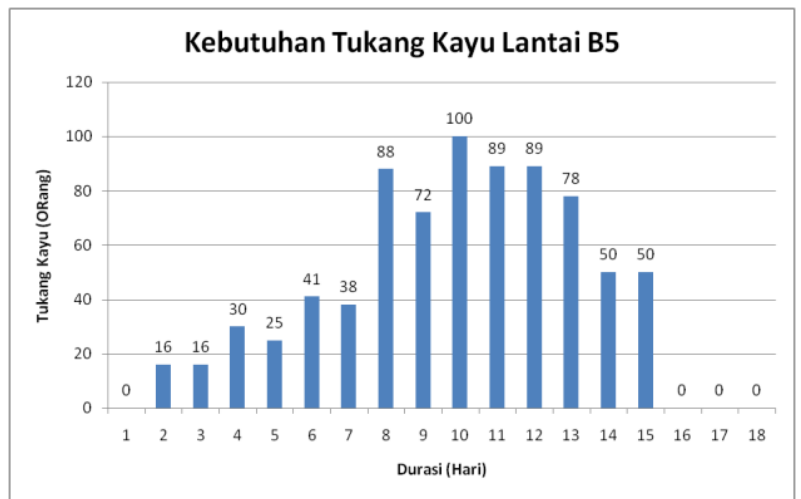

Gambar 3. Histogram tenaga kerja tukang kayu lantai B5 sebelum Resource Leveling

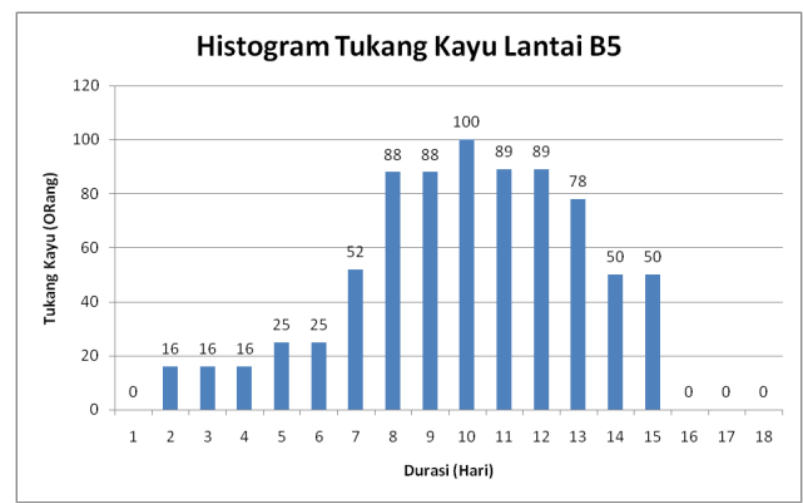

Gambar 4. Histogram tenaga kerja tukang kayu lantai B5 setelah Resource Leveling 
Pada penjadwalan awal pekerjaan bekisting lantai B5 yang dilakukan oleh tukang kayu, jumlah maksimum permintaan tenaga kerja tukang kayu per hari selama proyek berlangsung (MRD) untuk lantai B5 adalah 100 orang dan total jumlah tenaga kerja per hari yang tidak produktif (RID) untuk lantai B5 adalah 24 orang. Setelah dilakukan perataan, histogram pekerja menjadi seperti gambar 4 dengan nilai RID tukang batu menurun menjadi 0 orang dengan nilai MRD tetap.

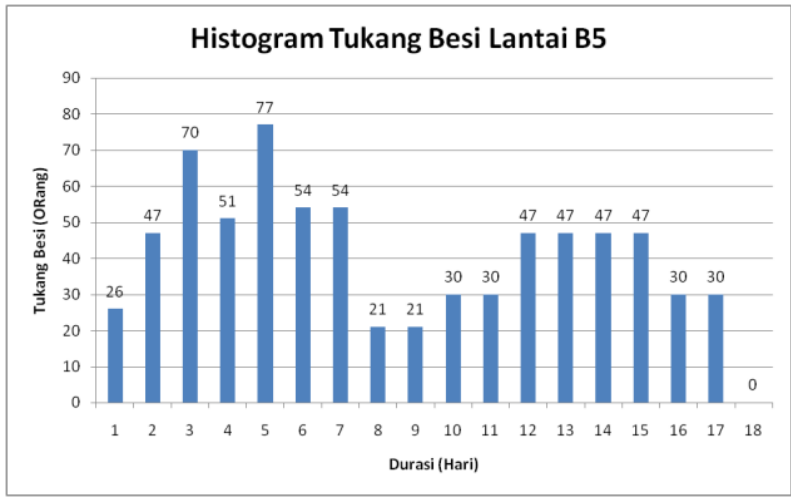

Gambar 5. Histogram tenaga kerja tukang besi lantai B5 sebelum Resource Leveling

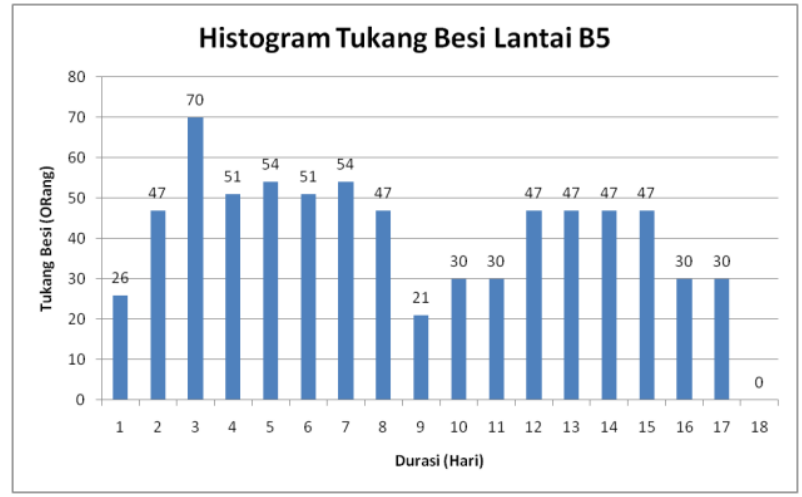

Gambar 6. Histogram tenaga kerja tukang besi lantai B5 setelah Resource Leveling

Pada gambar 5, pekerjaan pembesian lantai B5 yang dilakukan oleh tukang besi memiliki jumlah maksimum permintaan tenaga kerja tukang kayu per hari selama proyek berlangsung (MRD) untuk lantai B5 adalah 77 orang dan total jumlah tenaga kerja per hari yang tidak produktif (RID) untuk lantai B5 adalah 105 orang. Pada gambar 6 setelah dilakukan perataan, nilai RID tukang batu menurun menjadi 68 orang dan nilai MRD pun turun menajdi 70 orang.

\section{Hasil resource leveling lantai 2 - top roof}

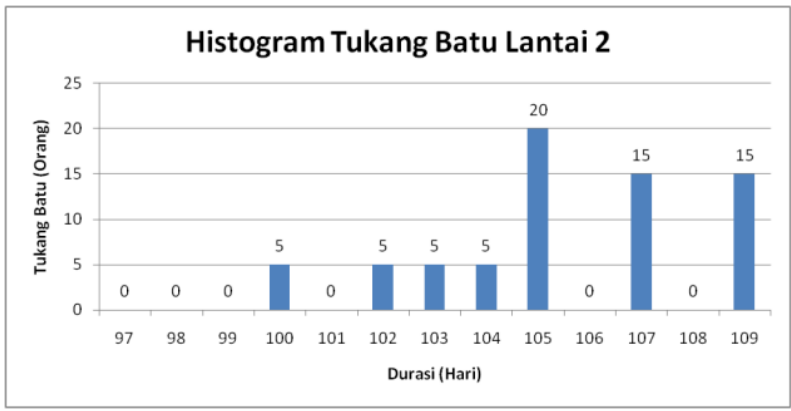

Gambar 7. Histogram tenaga kerja tukang batu lantai 2 sebelum Resource Leveling

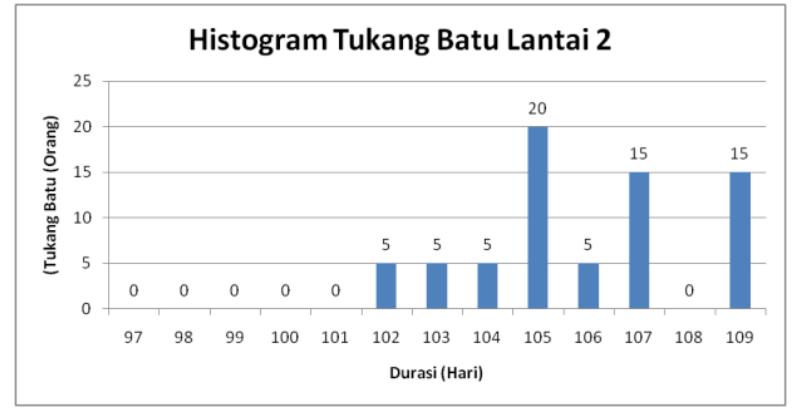

Gambar 8. Histogram tenaga kerja tukang batu lantai 2 setelah Resource Leveling

Seperti terlihat pada gambar 7, jumlah maksimum permintaan tenaga kerja tukang batu per hari selama proyek berlangsung (MRD) untuk lantai 2 adalah 20 orang dan total jumlah tenaga kerja per hari yang tidak produktif (RID) untuk lantai B5 adalah 35 orang. Setelah dilakukan perataan, nilai RID tukang batu menurun menjadi 25 orang dengan nilai MRD tetap. 


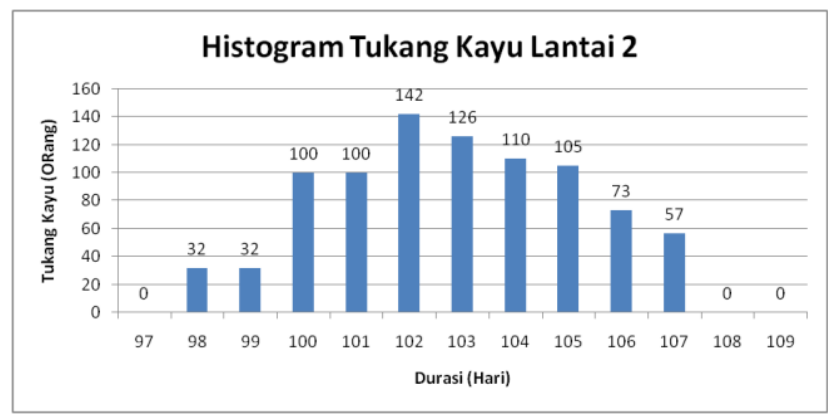

Gambar 9. Histogram tenaga kerja tukang kayu lantai 2

Dapat dilihat pada gambar 9, banyaknya tenaga kerja tukang kayu yang tidak produktif (RID) pada jadwal awal adalah 0 orang dengan jumlah maksimum permintaan tenaga kerja tukang kayu per hari (MRD) adalah 142 orang. Hasil analisis menggunakan program menunjukkan bahwa tidak terjadi pergeseran pada barchart. Hal ini mengindikasikan bahwa program tidak menemukan angka yang lebih baik dari nilai fungsi objektif semul. Oleh karenanya, pada pekerjaan bekisting kolom lantai 2 tidak terjadi pergeseran.

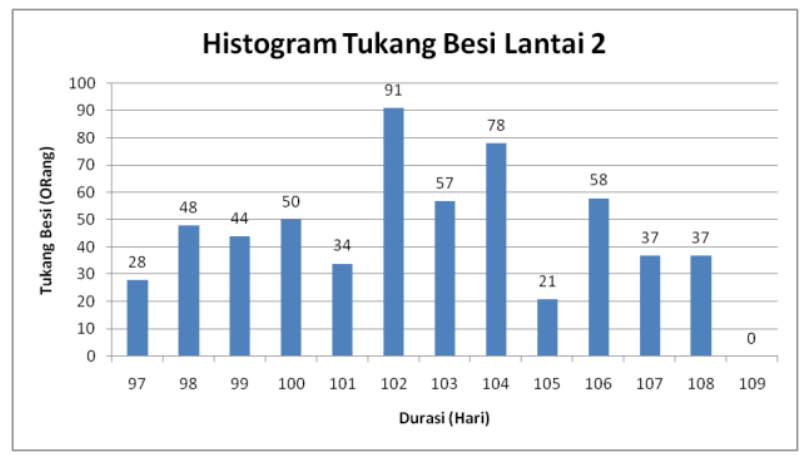

Gambar 10. Histogram tenaga kerja tukang besi lantai 2

Berdasarkan gambar 10, banyaknya tenaga kerja tukang besi yang tidak produktif (RID) pada jadwal awal adalah 78 orang dengan jumlah maksimum permintaan tenaga kerja tukang kayu per hari (MRD) adalah 91 orang. Pekerjaan pembesian kolom pada lantai 2 tidak dapat dilakukan pergeseran karena tidak memiliki free float yang dikarenakan tidak terdapat pergeseran pada pekerjaan bekisting kolom lantai 2.

\section{KESIMPULAN}

Berdasarkan analisis data yang telah dilakukan, dapat ditarik kesimpulan sebagai berikut:

1. Metode algoritma genetika dapat menurunkan jumlah tenaga kerja yang tidak produktif. Hal ini ditunjukkan dengan turunnya nilai RID (Resources Idle Days) pada tenaga kerja tukang batu, tukang kayu, dan tukang besi.

2. Tenaga kerja tukang batu lantai B5 hingga lantai GF mengalami penurunan nilai RID dari 75 orang menjadi 35 orang dengan nilai MRD tetap.

3. Tenaga kerja tukang kayu lantai B5 hingga lantai GF mengalami penurunan nilai RID dari 24 orang menjadi 0 orang dengan nilai MRD-yang tetap.

4. Tenaga kerja tukang besi lantai B5 hingga lantai GF mengalami penurunan nilai RID dari 105 orang menjadi 66 orang dan nilai MRD berkurang dari 77 orang menjadi 70 orang.

5. Tenaga kerja tukang batu lantai 2 hingga lantai top roof mengalami penurunan nilai RID dari 35 orang menjadi 25 orang dengan nilai MRD tetap.

6. Tenaga kerja tukang kayu dan besi lantai 2 hingga lantai top roof tidak mengalami penurunan nilai RID maupun MRD. 
7. Perataan tenaga kerja pada proyek $X$ ini menghasilkan persentase penurunan kebutuhan tenaga kerja tukang besi sebesar 9,1\% untuk lantai B5 hingga lantai GF.

\section{DAFTAR PUSTAKA}

Callahan, M. T., Quackenbush, D. G., and Rowings, J. E. (1992). Construction Project Scheduling. New York: McGraw-Hill.

Desiani, A. dan Arhami, M. (2005). Konsep Kecerdasan Buatan. Yogyakarta: Penerbit ANDI

El-Rayes, K., and Jun, D.H. (2009). "Optimizing Resource Leveling in Construction Projects” J. Constr. Eng. Manage., 10.1061/(ASCE)CO.1943-7862.0000097

Ervianto, Wulfram I. (2005). Manajemen Proyek Konstruksi. Yogyakarta: Andi Offset

Gen, M. and Cheng, R. (1997). Genetic Algorithm and Engineering Design. New York: John Wiley \& Sons, Inc.

Goldberg, D.E. (1989). Genetic Algorithms In Search, Optimization And Machine Learning. New York: AddisonWesley Publishing

Hegazy, T. (1999). “Optimization of Resource Allocation and Leveling Using Genetic Algorithms” J. Constr. Eng. Manage., 125(3), 167-175.

Kerzner, H. (1995). Project Management: A System Approach to Planning Scheduling, and Controlling (5 $5^{\text {th }}$ Edition). New York: Van Nostrand Reinhold Company

Kristanto, A. (2004). Jaringan Syaraf Tiruan (Konsep Dasar, Algoritma, dan Aplikasi). Yogyakarta: Gaya Media

Kusumadewi, Sri. (2003). Artificial Intelligence (Teknik dan Aplikasinya). Yogyakarta: Graha Ilmu.

Kusumadewi, Sri, dan Hari Purnomo. (2005). Penyelesaian Masalah Oprimasi dengan Teknik-Teknik Heuristik. Yogyakarta: Graha Ilmu

Matilla, K.G., and Abraham, D.M. (1998). "Resource Leveling of Linear Schedules using Integer Linear Programming”. J. Constr. Eng. Manage., 124(3), 232-244.

Nurhayati. (2010). Manajemen Proyek. Yogyakarta: Graha Ilmu

Oberlender, G.D. (1993), Project Management For Enginering And Construction. New York: McGraw-Hill

Prasetya, Hery, dan Lukiastuti, F. (2009). Manajemen Operasi. Jakarta: PT. Buku Kita

Santosa, B. (2009). Manajemen Proyek Konsep \& Implementasi. Yogyakarta: Graha Ilmu

Santosa, B., dan Ai, T.J. (2017). Pengantar Metaheuristik (Implementasi dengan Matlab). Surabaya: ITS Tekno Sains

Schwalbe, K. (2004). Information Technology Project Management ( $3^{\text {rd }}$ Edition). Canada: Thompson

Soeharto, I. (2001). Manajemen Proyek Jilid 2. Semarang: Erlangga

Steven, J. D. (1990). Technique for Construction Network Scheduling. United States: McGraw-Hill Companies 